\title{
Sacubitril/valsartan increases postprandial gastrin and cholecystokinin in plasma
}

\author{
Ulrik Ø Andersen ${ }^{1,2}$, Dijana Terzic ${ }^{1,2}$, Nicolai Jacob Wewer Albrechtsen ${ }^{1,2,3}$, Peter Dall Mark ${ }^{1,2}$, Peter Plomgaard ${ }^{1,4}$ \\ Jens F Rehfeld ${ }^{1}$, Finn Gustafsson ${ }^{5}$ and Jens P Goetze ${ }^{1,2}$ \\ ${ }^{1}$ Department of Clinical Biochemistry, Rigshospitalet, Copenhagen, Denmark \\ ${ }^{2}$ Institute of Biomedical Sciences, Faculty of Health and Medical Sciences, University of Copenhagen, Copenhagen, Denmark \\ ${ }^{3}$ Novo Nordisk Foundation Centre for Protein Research, Faculty of Health and Medical Sciences, University of Copenhagen, Copenhagen, Denmark \\ ${ }^{4}$ Department of Clinical Medicine, Faculty of Health and Medical Sciences, University of Copenhagen, Copenhagen, Denmark \\ ${ }^{5}$ Department of Cardiology, Rigshospitalet, Copenhagen, Denmark
}

Correspondence should be addressed to J P Goetze: JPG@dadlnet.dk

J P Goetze is a member of the editorial board of Endocrine Connections. He was not involved in the editorial or peer review process of this paper, on which he is listed as an author

\begin{abstract}
Aims: Neprilysin degrades natriuretic peptides in circulation and is also suggested to degrade the gut hormones gastrin and cholecystokinin. Neprilysin inhibition has become a therapeutic strategy and thus a regimen in need of further testing in terms of other hormonal axes besides natriuretic peptides. The aim of this study was to examine whether acute inhibition of neprilysin affects meal-induced responses in gastrin and cholecystokinin concentrations in healthy individuals.

Methods and results: Nine healthy young men were included in an open-labelled, randomized cross-over clinical trial. The participants received a standardized meal ( $25 \mathrm{~g}$ fat, $26 \mathrm{~g}$ protein, $42 \mathrm{~g}$ carbohydrate) on two separate days with or without a one-time dosage of sacubitril ((194 mg)/valsartan (206 mg)). Blood pressure, heart rate and blood samples were measured and collected during the experiment. Statistical differences between groups were assessed using area under the curve together with an ANOVA with a Bonferroni post hoc test. Sacubitril/valsartan increased the postprandial plasma concentrations of both gastrin and cholecystokinin ( $80 \%\left(\mathrm{AUC}_{0-270 \text { min }}, P=0.004\right)$ and $60 \%\left(\mathrm{AUC}_{0-270 \text { min }}, P=0.003\right)$, respectively) compared with the control meal. No significant hemodynamic effects were noted (blood pressure, $\mathrm{AUC}_{0-270 \text { min' }} P=0.86$, heart rate, $\mathrm{AUC}_{0-270 \min ^{\prime}} P=0.96$ ).

Conclusion: Our study demonstrates that sacubitril/valsartan increases the postprandial plasma concentrations of gastrin and cholecystokinin in healthy individuals. The results thus suggest that neprilysin-mediated degradation of gastrin and cholecystokinin is physiologically relevant and may have a role in heart failure patients treated with sacubitril/valsartan.
\end{abstract}
Key Words
- heart failure
- cholecystokinin
- gastrin
- natriuretic peptide
- sacubitril/valsartan
- neprilysin

\section{Introduction}

Chronic heart failure is treated by inhibition of the sympathetic and the renin-angiotensin-aldosterone system (RAAS). More recently, sacubitril/valsartan has been introduced as treatment for patients with chronic heart failure. The drug is composed of valsartan, an
angiotensin-II receptor 1 blocker, and sacubitril, which inhibits the peptide-degrading enzyme neprilysin (neutral endopeptidase 24.11) (1). Neprilysin degrades a plethora of peptide hormones, including atrial (ANP) and B-type (BNP) natriuretic peptides (2). Increased plasma https://ec.bioscientifica.com https://doi.org/10.1530/EC-19-0563 (c) 2020 The authors Published by Bioscientifica Ltd

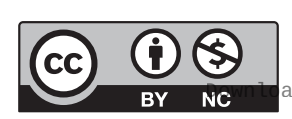

This work is licensed under a Creative Commons Attribution-NonCommercial 4.0 International License. ded from Bioscientifica.com at $04 / 26 / 2023$ 02:14:22PM 
concentrations of natriuretic peptides counteract the detrimental circulatory effects of heart failure, as they improve cardiac pre- and afterload by enhancing renal excretion of sodium and water, and also via vasodilatory effects. Importantly, it has also been shown that sacubitril/ valsartan reduces the mortality for patients with chronic heart failure (3).

Several other hormones, for instance glucagon-like peptide-1 (GLP-1) and substance P, are known substrates of neprilysin $(1,4)$. So far, only indirect experiments have suggested that neprilysin degrades gastrin and cholecystokinin (CCK) $(5,6,7,8,9,10)$. These hormones are secreted in parallel with GLP-1 from the endocrine gut after food intake. Gastrin regulates gastric acid secretion and growth of the fundic mucosa (11), whereas CCK regulates gallbladder contraction, satiety, and pancreatic exocrine and endocrine secretion $(11,12)$. Patients with chronic heart failure are now treated with sacubitril/ valsartan on a long-term basis, and it is therefore important to fully acknowledge the effects on all gut hormones. We thus examined the possible effects of acute neprilysin inhibition on the postprandial plasma concentrations of gastrin and CCK in healthy individuals.

\section{Methods}

The study was designed as an open-labelled, randomized trial and performed at the Department of Clinical Biochemistry (Rigshospitalet, University of Copenhagen). The Ethical Committee of The Capital Region of Denmark approved the protocol (H-18000360) and the study conformed to the Declaration of Helsinki. Before entering the trial, all subjects were informed in both oral and written form of the study protocol and the potential risks. At a consultation, height and weight were measured, and blood was collected as a general health check. Based on the results of the consultation, the subjects were either included or excluded. Eligible subjects were young, lean, and healthy males, all Caucasian. The inclusion and exclusion criteria are shown in Table 1 . The study protocol and patient characteristic has been reported previously (13).

\section{Study design}

The subjects were enrolled for two study days separated by a 2 -week washout period. The entire study was carried out over a period of 3 months. The subjects were initially randomized to receive either sacubitril/valsartan or no treatment on the first day of examination. Regardless of randomization, subjects fasted overnight (10 h) and the tests were performed the following morning. The subjects were placed in a supine position and a peripheral venous catheter was inserted into the cubital vein. On the day of treatment, two tablets of sacubitril/valsartan, $97 \mathrm{mg} / 103$ mg (C09DX04) (total dose of $194 \mathrm{mg}$ sacubitril/206 mg valsartan) were administrated orally $(\mathrm{t}=0 \mathrm{~min})$. On both days of examination, a standardized meal (a Big Mac burger containing $42 \mathrm{~g}$ carbohydrate, $25 \mathrm{~g}$ fat, and $26 \mathrm{~g}$ protein) (Big Mac, McDonalds; https://www.mcdonald s.com/dk/da-dk/product/big-mac.html) was ingested $(\mathrm{t}=30 \mathrm{~min})$. The meal was consumed within $5 \mathrm{~min}$ on both trial days. The dose for sacubitril/valsartan was chosen from the suggested doses for patients with heart failure; the time between the consumption of the drug and the beginning of meal intake was chosen on the basis of the given information for peak concentration of sacubitrilat in plasma (1-2 h).

During each trial day, a total of 12 blood samples per subject were collected in $6 \mathrm{~mL}$ ethylene diamine tetraacetate, and $4 \mathrm{~mL}$ lithium-heparin tubes at $-30,0,15,30$, $45,60,75,90,120,150,210$, and $270 \mathrm{~min}$; see Fig. 1 . The tubes were immediately centrifuged for $10 \mathrm{~min}$ at $2000 \boldsymbol{g}$ at $4^{\circ} \mathrm{C}$, and the plasma was transferred to tubes (Cryopure, ref. 72.379; Sarstedt, Nümbrecht, Germany) and false

Table 1 Criteria of inclusion and exclusion.

\begin{tabular}{l} 
Inclusion criteria \\
\hline Healthy \\
Male \\
Aged $18-30$ years \\
BMl between 20 and $25 \mathrm{~kg} / \mathrm{m}^{2}$ \\
Non-smoker \\
No use of daily medicine
\end{tabular}

\begin{tabular}{l}
\hline Exclusion criteria \\
\hline Drugs consumption \\
Weight loss cure \\
Donation of blood the past 2 weeks \\
Daily medicine \\
Normal blood sample results at the first consultation \\
Smoker \\
Weekly alcohol intake above 21 units \\
Pre-blood samples showing sign of disease
\end{tabular}

Table 1 list the in- and exclusion criteria of this study.

https://ec.bioscientifica.com

https://doi.org/10.1530/EC-19-0563 (c) 2020 The authors Published by Bioscientifica Ltd

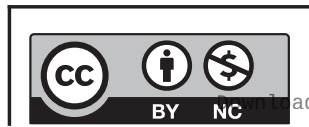

This work is licensed under a Creative Commons Attribution-NonCommercial 4.0 International License. ded from Bioscientifica.com at 04/26/2023 02:14:22PM 


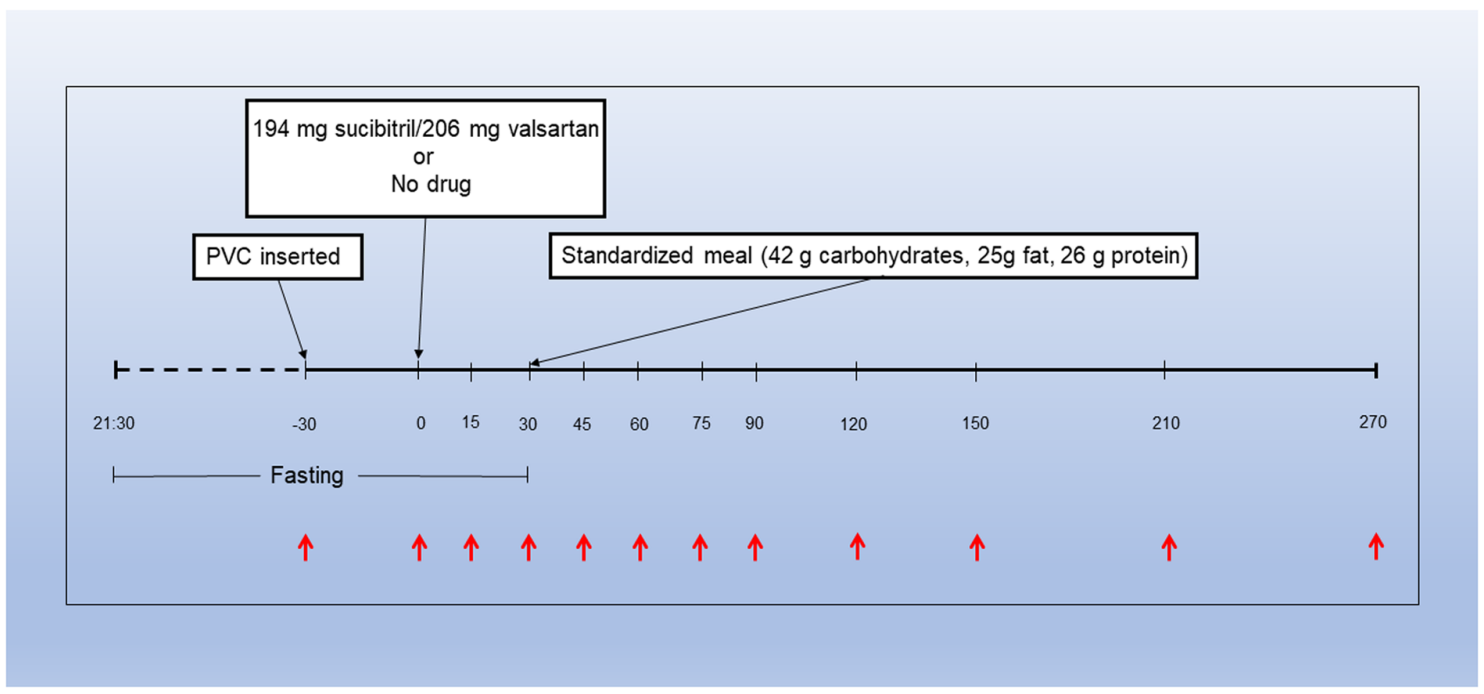

\section{Figure 1}

The subjects were fasting from 21:30 $\mathrm{h}$ the day before. A periphery venous catheter (PVC) was inserted, and baseline blood samples were collected before ingestion of sacubitril/valsartan (a total of $194 \mathrm{mg}$ sacubitril/206 mg valsartan). The standardized meal (42 $\mathrm{g}$ carbohydrate, $25 \mathrm{~g}$ fat, $26 \mathrm{~g}$ protein) was consumed 30 min after ingestion of the drug. Red arrows indicate when blood samples, blood pressure (BP), and heart rate (HR) were collected and measured.

bottom tubes (ref. 60.614.010; Sarstedt) and stored at $-80^{\circ} \mathrm{C}$. During the study, the subjects were allowed to drink a maximum of $500 \mathrm{~mL}$ of water.

\section{Biochemical analyses}

The plasma from the inclusion examination was analysed for standard biochemical parameters (COBAS 8000, Roche). During the trial, blood pressure and heart rate (HR) were measured using an Edan M3A Vital sign monitor. Plasma glucose was measured on a Cobas 8000, c702 module. Radioimmunoassays (RIAs) developed in the department were used to quantitate gastrin and CCK concentrations in plasma. The analytical and clinical validity of the RIAs has previously been reported (14, 15, 16). In brief, gastrin and CCK were measured using antiserum 2604 and antiserum 92128, respectively, which bind all bioactive forms of the two hormones and with no cross-reactivity between the two.

\section{Statistical analyses}

Data are presented as mean values with s.E.M. if not otherwise indicated. In the statistical analyses, we compared the mean value of the outcomes between the two trial days. Area under the curve (AUC) was calculated using the trapezoidal method and used to conduct a paired $T$-test. In addition, a mixed model ANOVA was used to compare gastrin CCK and gastrin concentrations with the control group followed by the Bonferroni post hoc test. The mixed-model ANOVA was chosen due to missing data at a few time-points. A two-way ANOVA followed by a post hoc Bonferroni was used to determine any potential differences of mean arterial pressure (MAP), HR, and glucose concentrations. For the statistical analysis, the program Prism 8 for Windows (Graphpad) was used. The level of significance was set at $P$ value $<0.05$.

\section{Results}

Ten healthy male subjects were screened for inclusion in the study. One dropped out after the initial consultation due to problems with adhering to the timeline of the study. The remaining subjects completed both trial days. Prior to the study, all subjects underwent a medical examination with all results within reference ranges. For baseline characteristics, see Table 2 .

\section{Hemodynamic response}

Baseline mean arterial pressure (MAP) was $91 \pm 2 \mathrm{mmHg}$ in the control group and $88 \pm 2 \mathrm{mmHg}$ in the sacubitril/ valsartan group (two-way ANOVA, $P>0.99$ ). In response to the ingestion of the meal, MAP decreased in both groups, but increased steadily $2 \mathrm{~h}$ after ingestion: There were no significant difference between the groups ( $\mathrm{tAUC}_{0-270 \mathrm{~min}}$ : $-762 \pm-1125$ vs $-652 \pm-1089 \mathrm{~min} \times \mathrm{mmHg}, P=0.86)$. In 
Table 2 Subject data.

\begin{tabular}{|c|c|c|c|}
\hline & Reference & Mean & S.E.M. \\
\hline Height (cm) & - & 185 & 2 \\
\hline Weight (kg) & - & 81 & 2 \\
\hline Age (years) & - & 24 & 1 \\
\hline $\mathrm{BMI}\left(\mathrm{kg} / \mathrm{m}^{2}\right)$ & - & 24 & 1 \\
\hline $\mathrm{Hb}(\mathrm{mmol} / \mathrm{L})$ & $8.3-9.5$ & 9.3 & 0.2 \\
\hline $\mathrm{K}(\mathrm{mmol} / \mathrm{L})$ & $3.5-4.4$ & 4.1 & 0.1 \\
\hline Creatinine ( $\mu \mathrm{mol} / \mathrm{L})$ & $60-105$ & 85.8 & 4.6 \\
\hline Sodium (mmol/L) & $137-145$ & 140.2 & 0.7 \\
\hline Albumin (g/L) & $36-48$ & 42.2 & 0.8 \\
\hline $\mathrm{CRP}(\mathrm{mg} / \mathrm{L})$ & $<5$ & 1.1 & 0.1 \\
\hline $\operatorname{ALAT}(\mathrm{U} / \mathrm{L})$ & $10-70$ & 26.1 & 5.0 \\
\hline $\begin{array}{l}\mathrm{HbA} 1 \mathrm{C}(\mathrm{IFCC}) \text { (mmol/ } \\
\text { mol) }\end{array}$ & $31-44$ & 30.8 & 0.9 \\
\hline Glucose $(\mathrm{mmol} / \mathrm{L})^{\mathrm{a}}$ & $4.2-6.3$ & 5.3 & 0.1 \\
\hline $\begin{array}{l}\text { Total cholesterol } \\
\text { (mmol/L) }\end{array}$ & $<5$ & 4.2 & 0.3 \\
\hline HDL (mmol/L) & $>1$ & 1.3 & 0.1 \\
\hline LDL (mmol/L) & $<3$ & 2.8 & 0.4 \\
\hline Triglycerides (mmol/L) & $<2$ & 1.1 & 0.4 \\
\hline
\end{tabular}

Table 2 list the anthropometrics and biochemical results at consultation before entering the study.

aGlucose reference interval is in a fasting state, but the blood samples were collected at a pre-interview in a not-fasting state.

parallel, heart rate (HR) decreased in both groups during the $30 \mathrm{~min}$ before ingestion of the meal. No response to ingestion of sacubitril/valsartan was observed, but in response to food intake, HR increased in both groups with a peak of $67 \pm 3 \mathrm{bpm}$ in the sacubitril/valsartan group vs $62 \pm 3 \mathrm{bpm}$ in the control group. No significant difference $\left(\mathrm{tAUC}_{0-270 \mathrm{~min}}: 52 \pm 63\right.$ sacubitril/valsartan group vs $46 \pm 57$ control group $\min \times \mathrm{bpm}, P=0.98$ ) was noted between trial the days.

\section{Glucose concentration}

There was no significant difference in glucose plasma concentration in response to ingestion of sacubitril/ valsartan and a meal between the two groups (peak $6.7 \pm 0.3$ vs $6.7 \pm 0.2 \mathrm{mmol} / \mathrm{L}, P>0.99: \mathrm{tAUC}_{0-270 \mathrm{~min}}: 76 \pm 93$ vs $63 \pm 81, P=0.67)$.

\section{Gastrin and CCK response}

The gastrin concentration in plasma rapidly increased after consumption of the standardized meal. Combined with intake of sacubitril/valsartan, the increase was markedly enhanced; AUC was $80 \%$ greater compared with the control group ( $\mathrm{tAUC}_{0-270 \mathrm{~min}}: 1263 \pm 56$ vs $710 \pm 77$ min $\times$ pmol/L, $P=0.004$, Fig. $2 A)$. Ninety minutes after meal intake, the concentrations were similar in the two groups and they continued to be so throughout the remaining study period.
The baseline CCK concentrations in plasma did not differ between the trial days (mixed model ANOVA, $P>0.99$ ). The plasma concentration increased after ingestion of a meal with and without sacubitril/valsartan. The AUC was $60 \%$ higher when subjects received sacubitril/valsartan (tAUC ${ }_{0-270 \text { min }}: 487 \pm 207$ vs. $308 \pm 115$ $\min \times \mathrm{pmol} / \mathrm{L}, P=0.003)$; see Fig. $2 \mathrm{~B}$.

\section{Discussion}

The present study shows that acute inhibition of neprilysin with sacubitril/valsartan increases the postprandial plasma concentrations of gastrin and cholecystokinin (CCK) in healthy young men. Previous studies have suggested a proteolytic effect of neprilysin on gastrin and CCK using indirect methods $(7,8,9,17$, $18,19)$. Specifically, the effect of neprilysin was suggested through chromatographic comparison of endogenous peptide fragments with incubation of synthetic peptides and enzyme in vitro. A major difference between our study and the earlier in vitro studies was the former use of CCK and gastrin synthetic peptides together with neprilysin of non-human origin, which complicates the interpretation in relation to human physiology. One human study (9) did infuse human gastrin (gastrin-17) into healthy humans and evaluated the circulating fragments over time using gel chromatography. The study concluded on a possible degrading effect of neprilysin. However, no direct link was established to specific neprilysin degradation. The results of our human study show that targeted neprilysin inhibition immediately alters the gastrin and CCK concentrations after a meal in healthy young men.

The present report is mainly an exploratory study. The drug is indicated for patients with chronic heart failure and reduced ejection fraction, thus receiving daily drug doses for years. The long-term effect of neprilysin inhibition on gastrin and CCK concentrations is still unknown, but it seems reasonable to hypothesize that the plasma concentrations will also increase in patients with heart failure and during chronic therapy. Gastrin regulates proliferation and growth of the gastric mucosa and studies have indicated that long-term hypergastrinemia in humans induces hyperplasia and dysplasia of the gastric mucosa $(20,21,22)$. It is unknown if the peaks of gastrin seen in this study is sufficient to induce hyperplasia in human. Whether hypergastrinemia will follow long-term treatment with sacubitril/valsartan needs to be examined, and if so, whether this increase is associated with an increase in gastric disorders such as dyspeptic pain and duodenal ulcers.

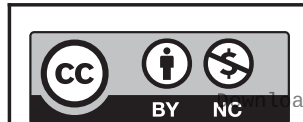

This work is licensed under a Creative Commons Attribution-NonCommercial 4.0 International License. ded from Bioscientifica.com at 04/26/2023 02:14:22PM 

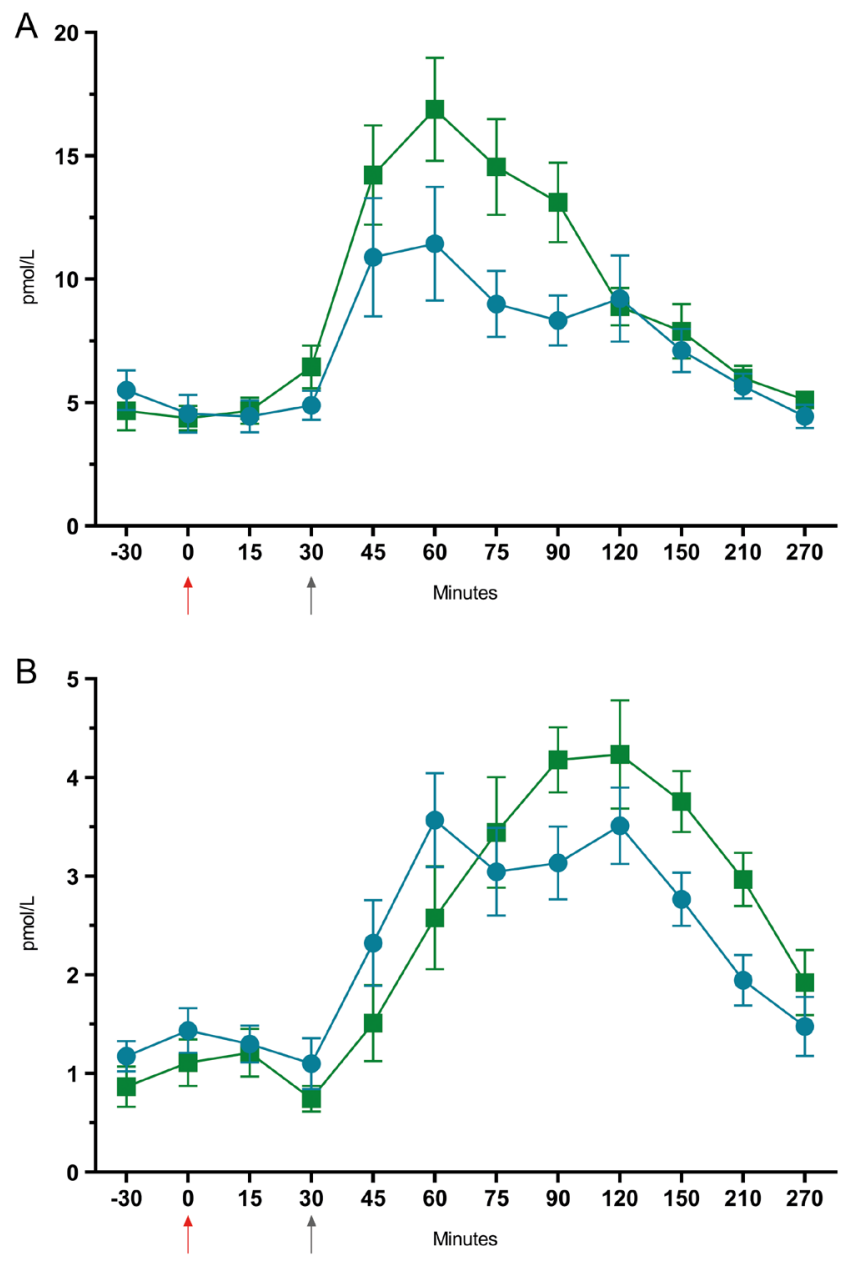

\section{Figure 2}

The subjects were randomized to not receive (blue circles) or to receive a single dose of two tablets of sacubitril/valsartan (a total of $194 \mathrm{mg}$ sacubitril/206 mg valsartan) (green squares) and afterward a standardized meal. The red arrow represents the time sacubitril/valsartan was given and the grey arrow indicates administration of the standardized meal. Panel A and B shows the effect on gastrin and CCK concentrations, respectively.

A seminal study on sacubitril/valsartan treatment in heart failure patients has shown improved glycemic control in patients with both chronic heart failure and diabetes (23). While it remains unresolved exactly how sacubitril/valsartan improves the glycemic control, several mechanisms have been suggested including increased plasma concentrations of the incretin hormone GLP-1 (23). We have recently reported that sacubitril/valsartan increases total but not intact GLP-1 concentrations in healthy humans (13). Other hormonal contributors behind the decrease in HbA1c values observed in patients could be CCK and gastrin, as both are also incretin hormones. The endocrine pancreas expresses gastrin/ $\mathrm{CCK}_{2}$ receptors, and several studies have shown that these hormones have an insulinotropic effect $(24,25$, $26,27)$. Another possibility could be that CCK inhibits gastric motility (28), which will delay gastric emptying. This could also contribute to reducing the postprandial hyperglycemia seen in type 2 diabetes. Whether the earlier observed decrease in HbA1c is mediated mainly by one hormone system or, rather, several operating in concert, needs to be examined further. Finally, it should be recapitulated that a treatment which improves hemodynamic function in heart failure also will have an (positive) impact in physical activity of the patients and thereby contribute to decrease in $\mathrm{HbA1c}$.

Gastrin and CCK both circulate in multiple molecular forms (29). The differences between the molecular forms are mainly defined by the N-terminal part of their structuresa, whereas the active/receptor binding part of the hormones resides in the C-terminal sequence. In this study, we only used immunoassays specific for the receptor binding part of the hormones, and as such, we thus report on the concentrations of the bioactive parts of gastrin and CCK. Several proteases are involved in the elimination of gastrin and CCK peptides, and mainly the $\mathrm{N}$-terminus of CCK peptides is subject to cleavage and degradation in vivo by aminopeptidases. In contrast, the predominant gastrin forms (gastrin-34 and gastrin-17) are protected against aminopeptidases by pyroglutamination. In perspective, examining the different molecular forms of gastrin and CCK in relation to NEP inhibition could prove worthwhile to pursue.

This exploratory study has several limitations. Treatment with sacubitril/valsartan is indicated for patients with chronic heart failure, and this study was conducted on young healthy male subjects. A second limitation is the chosen dosage. The recommended dosage of sacubitril/valsartan is $49 \mathrm{mg} / 51 \mathrm{mg}$ through weeks of upscaling until an endpoint of $97 \mathrm{mg} / 103 \mathrm{mg}$, twice daily. In this study, the subjects received two tablets of 97 $\mathrm{mg} / 103 \mathrm{mg}$, a total of $194 \mathrm{mg}$ sacubitril/206 mg valsartan, once. This is two- to four-fold the recommended dosage, and it would, therefore, be relevant to examine if subjects receiving the clinical dosage have the same response as this study shows. Finally, this is an acute study of sacubitril/valsartan treatment, and whether the effect of long-term use of sacubitril/valsartan augments gastrin and CCK concentrations in circulation in patients with chronic heart failure is not clear.

In conclusion, this exploratory study shows that acute neprilysin inhibition with sacubitril/valsartan increases the meal-related concentrations of gastrin and CCK in plasma. Further studies including patients with chronic

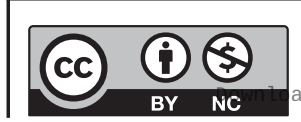

This work is licensed under a Creative Commons Attribution-NonCommercial 4.0 International License. ded from Bioscientifica.com at 04/26/2023 02:14:22PM via free access 
heart failure receiving sacubitril/valsartan are now needed to clarify the potential effects and their possible association to stomach-related disease.

\section{Declaration of interest}

Jens Peter Goetze is a Senior Editor for Endocrine Connections. He was not involved in the editorial or peer review process of this paper, on which he is listed as an author. The other authors have nothing to disclose.

\section{Funding}

This research did not receive any specific grant from any funding agency in the public, commercial or not-for-profit sector

\section{Acknowledgements}

The authors are grateful for the technical assistance of Alice von der Lieth and Marie Zeibell Severinsen.

\section{References}

1 Hubers SA \& Brown NJ. Combined angiotensin receptor antagonism and neprilysin inhibition. Circulation 2016133 1115-1124. (https:// doi.org/10.1161/CIRCULATIONAHA.115.018622)

2 Olins GM, Krieter PA, Trapani AJ, Spear KL \& Bovy PR. Specific inhibitors of endopeptidase 24.11 inhibit the metabolism of atrial natriuretic peptides in vitro and in vivo. Molecular and Cellular Endocrinology 198961 201-208. (https://doi.org/10.1016/03037207(89)90131-7)

3 McMurray JJ, Packer M, Desai AS, Gong J, Lefkowitz MP, Rizkala AR, Rouleau JL, Shi VC, Solomon SD, Swedberg K, et al. Angiotensinneprilysin inhibition versus enalapril in heart failure. New England Journal of Medicine 2014371 993-1004. (https://doi.org/10.1056/ NEJMoa1409077)

4 Campbell DJ. Long-term neprilysin inhibition - implications for ARNIs. Nature Reviews: Cardiology 201714 171-186. (https://doi. org/10.1038/nrcardio.2016.200)

5 Deschodt-Lanckman M \& Strosberg AD. In vitro degradation of the C-terminal octapeptide of cholecystokinin by 'enkephalinase A'. FEBS Letters 1983152 109-113. (https://doi.org/10.1016/00145793(83)80493-1)

6 Matsas R, Kenny AJ \& Turner AJ. The metabolism of neuropeptides. The hydrolysis of peptides, including enkephalins, tachykinins and their analogues, by endopeptidase-24.11. Biochemical Journal 1984 223 433-440. (https://doi.org/10.1042/bj2230433)

7 Najdovski T, Collette N \& Deschodt-Lanckman M. Hydrolysis of the C-terminal octapeptide of cholecystokinin by rat kidney membranes characterization of the cleavage by solubilized endopeptidase-24.11. Life Sciences 198537 827-834. (https://doi.org/10.1016/00243205(85)90517-x)

8 Bunnett NW, Debas HT, Turner AJ, Kobayashi R \& Walsh JH. Metabolism of gastrin and cholecystokinin by endopeptidase 24.11 from the pig stomach. American Journal of Physiology 1988255 G676-G684. (https://doi.org/10.1152/ajpgi.1988.255.5.G676)

9 Deschodt-Lanckman M, Pauwels S, Najdovski T, Dimaline R \& Dockray GJ. In vitro and in vivo degradation of human gastrin by endopeptidase 24.11. Gastroenterology 198894 712-721. (https://doi. org/10.1016/0016-5085(88)90244-2)

10 Pauwels S, Najdovski T, Dimaline R, Lee CM \& DeschodtLanckman M. Degradation of human gastrin and CCK by endopeptidase 24.11: differential behaviour of the sulphated and unsulphated peptides. Biochimica et Biophysica Acta 1989996 82-88. (https://doi.org/10.1016/0167-4838(89)90098-8)

11 Dockray GJ. Clinical endocrinology and metabolism. Gastrin. Best Practice and Research: Clinical Endocrinology and Metabolism 200418 555-568. (https://doi.org/10.1016/j.beem.2004.07.003)

12 Rehfeld JF \& Local Gut C-F. Hormone to ubiquitous messenger. Frontiers in Endocrinology 2017847.

13 Wewer Albrechtsen NJ, Mark PD, Terzic D, Hansen LH, Andersen UØ, Hartmann B, Carr RD, Gustafsson F, Deacon CF, Holst JJ, et al. Sacubitril/valsartan augments postprandial plasma concentrations of active GLP-1 when combined with sitagliptin in men. Journal of Clinical Endocrinology and Metabolism 2019 104 3868-3876. (https:// doi.org/10.1210/jc.2019-00515)

14 Stadil F \& Rehfeld JF. Radioimmunoassay of gastrin in human serum. Scandinavian Journal of Gastroenterology: Supplement 19719 61-65.

15 Rehfeld JF. Accurate measurement of cholecystokinin in plasma. Clinical Chemistry 199844 991-1001. (https://doi.org/10.1093/ clinchem/44.5.991)

16 Rehfeld JF, Gingras MH, Bardram L, Hilsted L, Goetze JP \& Poitras P. The Zollinger-Ellison syndrome and mismeasurement of gastrin. Gastroenterology 2011140 1444-1453. (https://doi.org/10.1053/j. gastro.2011.01.051)

17 Matsas R, Turner AJ \& Kenny AJ. Endopeptidase-24.11 and aminopeptidase activity in brain synaptic membranes are jointly responsible for the hydrolysis of cholecystokinin octapeptide (CCK8). FEBS Letters 1984175 124-128. (https://doi.org/10.1016/00145793(84)80583-9)

18 Power DM, Bunnett N, Turner AJ \& Dimaline R. Degradation of endogenous heptadecapeptide gastrin by endopeptidase 24.11 in the pig. American Journal of Physiology 1987253 G33-G39. (https://doi. org/10.1152/ajpgi.1987.253.1.G33)

19 Medeiros Mdos S \& Turner AJ. Comparison of cholecystokinin metabolism by membrane preparations from the human astrocytoma clone D384 and the neuroblastoma line SH-SY5Y. Neurochemistry International 199424 369-377. (https://doi.org/10.1016/01970186(94)90115-5)

20 Larsson LI, Rehfeld JF, Stockbrügger R, Blohme G, Schöön IM, Lundqvist G, Kindblom LG, Säve-Söderberg J, Grimelius L \& Olbe L. Mixed endocrine gastric tumors associated with hypergastrinemia of antral origin. American Journal of Pathology 197893 53-68.

21 Havu N, Mattsson H, Ekman L \& Carlsson E. Enterochromaffinlike cell carcinoids in the rat gastric mucosa following long-term administration of ranitidine. Digestion 199045 189-195. (https://doi. org/10.1159/000200245)

22 Hakanson R \& Sundler F. Proposed mechanism of induction of gastric carcinoids: the gastrin hypothesis. European Journal of Clinical Investigation 199020 (Supplement 1) S65-S71. (https://doi. org/10.1111/j.1365-2362.1990.tb01780.x)

23 Seferovic JP, Claggett B, Seidelmann SB, Seely EW, Packer M, Zile MR, Rouleau JL, Swedberg K, Lefkowitz M, Shi VC, et al. Effect of sacubitril/valsartan versus enalapril on glycaemic control in patients with heart failure and diabetes: a post-hoc analysis from the PARADIGM-HF trial. Lancet: Diabetes and Endocrinology 20175 333-340. (https://doi.org/10.1016/S2213-8587(17)30087-6)

24 Rehfeld JF \& Stadil F. The effect of gastrin on basal- and glucosestimulated insulin secretion in man. Journal of Clinical Investigation 197352 1415-1426. (https://doi.org/10.1172/JCI107315)

25 Rehfeld JF, Larsson LI, Goltermann NR, Schwartz TW, Holst JJ, Jensen SL \& Morley JS. Neural regulation of pancreatic hormone secretion by the C-terminal tetrapeptide of CCK. Nature 1980284 33-38. (https://doi.org/10.1038/284033a0)

26 Hermansen K. Effects of cholecystokinin (CCK)-4, nonsulfated CCK-8, and sulfated CCK-8 on pancreatic somatostatin, insulin, and glucagon secretion in the dog: studies in vitro. Endocrinology 1984 114 1770-1775. (https://doi.org/10.1210/endo-114-5-1770) https://ec.bioscientifica.com https://doi.org/10.1530/EC-19-0563 (c) 2020 The authors Published by Bioscientifica Ltc

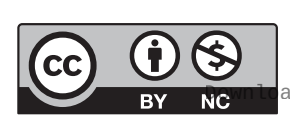

This work is licensed under a Creative Commons Attribution-NonCommercial 4.0 International License. ded from Bioscientifica com at 04/26/2023 02:14:22PM 
27 Reubi JC, Waser B, Gugger M, Friess H, Kleeff J, Kayed H, Büchler MW \& Laissue JA. Distribution of CCK1 and CCK2 receptors in normal and diseased human pancreatic tissue. Gastroenterology 2003125 98-106. (https://doi.org/10.1016/s0016-5085(03)00697-8)

28 Castillo EJ, Delgado-Aros S, Camilleri M, Burton D, Stephens D, O'Connor-Semmes R, Walker A, Shachoy-Clark A \& Zinsmeister AR. Effect of oral CCK-1 agonist GI181771X on fasting and postprandial gastric functions in healthy volunteers. American Journal of Physiology: Gastrointestinal and Liver Physiology 2004287 G363-G369. (https://doi.org/10.1152/ajpgi.00074.2004)

29 Rehfeld JF, Friis-Hansen L, Goetze JP \& Hansen TV. The biology of cholecystokinin and gastrin peptides. Current Topics in Medicinal Chemistry 20077 1154-1165. (https://doi. org/10.2174/156802607780960483)

Received in final form 23 April 2020

Accepted 28 April 2020

Accepted Manuscript published online 28 April 2020
This work is licensed under a Creative Commons Attribution-NonCommercial 4.0 International License. 